\title{
Estudio seroepidemiológico del virus respiratorio sincitial bovino en el municipio de Montería, Colombia
}

\section{Seroepidemiological study of the bovine respiratory sincitial virus in the municipality of Monteria, Colombia}

\author{
César Betancur H, ${ }^{1 * M . S c}$, Juan Rodas G, ${ }^{2}$ Ph.D, Marco González T, ${ }^{1}$ M. Sc.
}

\begin{abstract}
${ }^{1}$ Universidad de Córdoba, Departamento de Ciencias Pecuarias, Facultad Medicina Veterinaria y Zootecnia. Montería, Colombia. ${ }^{2}$ Universidad de Antioquia, Facultad de Ciencias Agrarias, Grupo Centauro. Medellín, Colombia. *Correspondencia:betanci@yahoo.com
\end{abstract}

Recibido: Mayo de 2010; Aceptado: Abril de 2011.

\section{RESUMEN}

Objetivo. El propósito de esta investigación fue realizar un estudio seroepidemiológico para detectar anticuerpos específicos contra el Virus Respiratorio Sincitial Bovino (BRSV) mediante la técnica comercial de ELISA (Bio-X @ BRSV Elisa Kit, Bruselas, Bélgica), con el fin de demostrar de manera indirecta, la presencia y circulación del VRSB en el municipio de Montería, Colombia. Materiales y métodos. Se recolectaron 163 muestras de sangre (137 de hembras y 26 de toros) de animales con antecedentes de infertilidad, pertenecientes a 28 fincas, los cuales provenían de 4 diferentes zonas equidistantes dentro del municipio. Todas las muestras fueron seleccionadas al azar. Se realizó un análisis descriptivo con los datos serológicos obtenidos de cada animal e interpretándolos con las variables: raza, edad, zona, tipo de explotación, sexo y alteraciones reproductivas. Para determinar la asociación entre seropositividad y cada una de las variables se utilizó la prueba de $\chi^{2}$. No hubo diferencias significativas para ninguna de las variables analizadas. Resultados. Se detectaron anticuerpos en 22 de los animales seleccionados, lo que correspondió al $13 \%$ del total muestreado. Conclusiones. Este hallazgo constituye la demostración indirecta de la presencia del VRSB en el municipio de Montería, lo que sugiere la necesidad de estudios adicionales para determinar su participación en síndromes respiratorios y problemas reproductivos; de comprobarse sus implicaciones clínicas en hatos bovinos de esta región, sería necesario implementar medidas adecuadas para su control y prevención.

Palabras clave: Bovinos, VRSB, Colombia, reproducción, serología (Fuente: CAB). 


\section{ABSTRACT}

Objective. To detect specific antibodies against the Bovine Respiratory Sincitial Virus (BRSV) through a commercial ELISA kit (Bio-X @ BRSV Elisa Kit, Bruselas, Bélgica) in order to have an indirect evidence of BRSV circulation, municipality of Monteria, Colombia. Materials and methods. A total of 163 blood samples were randomly collected (137 females and 26 bulls) from 28 farms belonging to 4 different equidistant zones and with an history of reproductive disorders. A descriptive $\chi^{2}$ analysis was performed to compared the serological results from each animal on breed, age, zone, type of production, sex and reproductive disorders. Results. There were no differences for any of the variables studied. Antibodies for BRSV were detected in 13\% (22/163) of the animals. Conclusions. The results show an indirect evidence of the presence of BRSV in animals belonging to the region studied. This suggests the need for additional studies in order to determine the participation of BRSV on respiratory and reproductive problems. If case of clinic implications, it would be necessary to implement appropriate control measures to prevent viral dissemination.

Key words: Bovines, BRSV, Colombia, reproduction, serology (Source: CAB).

\section{INTRODUCCIÓN}

El primer virus respiratorio sincitial (VRS), fue aislado inicialmente en humanos en 1959 (1), siendo reconocido solo hasta 1970, un agente similar en el ganado bovino (2). Este último fue detectado por primera vez en Japón, Bélgica y Suiza, luego se difundió a muchos otros países del mundo (3). En Estados Unidos, el primer aislamiento de virus respiratorio sincitial bovino (VRSB) fue reportado en 1974 en Iowa y Missouri (4).

EI VRSB así como el humano fue denominado así por el efecto citopático que producen in vitro, consistente con la formación de sincitios, los cuales se definen como células multinucleadas, producidas por unión o fusión celular. Además se ha reportado que puede producir cuerpos de inclusión intracitoplasmáticos y eosinófilos (5).

El VRSB, es un virus envuelto con genoma ARN, clasificado dentro del género pneumovirus de la familia Paramixoviridae. Dentro de este grupo, se incluyen otros agentes similares en especies domésticas, tales como virus sincitial respiratorio humano, al virus sincitial respiratorio de la cabra y el virus sincitial respiratorio de la oveja (6).
Aunque el VRSB ha sido ampliamente estudiado durante los últimos 10 años, su epidemiología aún no es lo suficientemente clara (7). Se han reportado mundialmente, prevalencias superiores al $65 \%$ (8), y niveles aún mayores de anticuerpos contra el VRSB, $65 \%$ a $85 \%$, han sido reportados, en Estados Unidos, previos a la introducción de vacunas (9).

No ha habido reportes de diferencias de susceptibilidad o severidad de enfermedad entre machos y hembras y la infección por VRSB, aparentemente puede observarse en cualquier grupo etario, pero las infecciones que resultan en una enfermedad clínica severa, son típicamente observadas en terneros menores de seis meses (10). No obstante, también existen reportes de infecciones por VRSB causando signos severos de enfermedad respiratoria en ganado adulto (11).

Las infecciones por VRSB ocurren tanto en ganadería de carne como en lechería, aunque existen reportes que sugieren diferencias en susceptibilidad a la infección y a la enfermedad producida por VRSB entre distintas razas (5). 
Las infecciones virales respiratorias causadas por Herpesvirus bovino tipo 1, DVB, Parainfluenza tipo 3 y virus sincitial respiratorio bovino (VSRB), son una parte significativa del Síndrome Respiratorio Bovino (SRB), también llamado "Fiebre de embarque". Sin embargo, a pesar de su trascendencia, es poca la importancia que se le ha prestado al estudio del comportamiento epidemiológico del VRSB en nuestro medio, así como a su compromiso en este tipo de síndrome y su asociación con problemas de infertilidad bovina (12).

Experimentalmente se ha logrado demostrar que infecciones concurrentes de VRSB y el Virus de la Diarrea Bovina (DVB), desarrollan un cuadro clínico con lesiones severas y leucopenia (13). De acuerdo con lo anterior, se considera necesario fomentar al menos el diagnóstico serológico de este tipo de agentes, para llegar a conocer su efecto sobre la salud pública veterinaria.

Existen varias vacunas comerciales para aplicación en bovinos (14), y desafortunadamente, algunas de ellas ya están siendo aplicadas en nuestro medio, sin que se tengan aún estudios serios, que demuestren su efectividad en pruebas de campo, y desvirtuando de paso, los estudios con base en respuesta serológica en animales vacunados.

EI VRSB aún no ha sido aislado en Colombia, pero su presencia se ha sospechado desde comienzos de la época de los 60s, lo cual amerita la realización de estudios que permitan un mejor conocimiento de la distribución de ésta entidad en nuestro medio, y de esta forma establecer su real impacto en la ganadería bovina del trópico (15).

El objetivo de este trabajo fue realizar un estudio seroepidemiológico para detectar anticuerpos específicos contra el Virus Respiratorio Sincitial Bovino con el fin de demostrar de manera indirecta, su presencia y circulación en el municipio de Montería, Colombia.

\section{MATERIALES Y MÉTODOS}

Sitio de estudio. El trabajo se desarrolló en el municipio de Montería, departamento de Córdoba, cuya temperatura promedio oscila entre 28 y $35^{\circ} \mathrm{C}$. Posee además una humedad relativa del $85 \%$ y una precipitación anual de 1200 a 1500 mm. El área municipal es de $3043 \mathrm{Km}^{2}$, y esta conformada por 27 corregimientos (16).

Tipo de estudio. La investigación propuesta corresponde a un estudio epidemiológico de tipo descriptivo transversal o de corte.

Selección de la muestra. El tamaño de la muestra se determinó mediante el programa estadístico EPI-INFO 2000 versión 6.0 CDC, Atlanta, GA, USA, utilizando una confiabilidad del $95 \%$ y un error de estimación no mayor al 5\% y correspondió a 108 animales; sin embargo, en el presente estudio se utilizaron 163 sueros de 137 hembras bovinas y 26 toros provenientes de 28 fincas distribuidas en el municipio de Montería, Colombia. Este municipio declaró al momento del estudio una población de 178.320 hembras mayores de 2 años (17). Como criterios de inclusión para la selección de los animales de la muestra, se tuvieron en cuenta las hembras repetidoras (más de tres servicios sin gestación) y/o que tuvieron reporte de abortos (tempranos o tardíos) y no tuvieran historia de vacunación. El estudio fue realizado a través de las evaluaciones reproductivas rutinarias que se adelantaron en cada explotación. Asimismo, se obtuvo información referente a identificación del animal edad, raza, tipo de explotación y estado reproductivo, variables necesarias para la correlación con la seropositividad a VRSB.

Obtención del suero. Previa desinfección del sitio de punción del animal, se colectaron $10 \mathrm{ml}$ de sangre en la vena yugular o coccígea. La sangre fue recogida en tubos vacutainer sin anticoagulante para obtener el suero por métodos estándares conocidos. 
Determinación de anticuerpos específicos contra VRSB. Para determinar el nivel de anticuerpos específicos contra el VRSB, se utilizó el kit comercial: BRSV ELISA KIT de Bio-XR, el cual usa una prueba indirecta de ELISA, donde se utilizó un antígeno de VRSB y un antígeno celular control. Para la interpretación de los resultados a los valores de densidad óptica (DO) de cada suero se le sustrajeron los valores correspondientes de los controles de antígeno. Las muestras cuyos valores fueron mayores o iguales a 30 de DO con una longitud de onda de $450 \mathrm{~nm}$, se consideraron positivas y las inferiores a este valor negativas.

Análisis estadístico. Se utilizó la prueba de independencia apoyada en la distribución Ji cuadrado $\left(X^{2}\right)$, y el coeficiente de contingencia (correlación) de Pearson. Los resultados para las distintas variables, se obtuvieron utilizando el paquete estadístico SPSS versión 11 (18).

\section{RESULTADOS}

De las 163 muestras analizadas, se encontraron anticuerpos en 22 animales, indicando una seropositividad del $13 \%$ con un intervalo de confianza del $95 \%$ entre el $11.37 \%$ y $14.63 \%$.

Análisis de las variables. Los siguientes fueron los resultados según las variables analizadas:

En la tabla 1 se reporta que la mayor frecuencia de animales seropositivos al VRSB se encontró en la zona Este (22.5\% de la muestra y $5.5 \%$ del total de los animales muestreados). En las

Tabla 1. Seropositividad y seronegatividad al VRSB en 4 zonas del municipio de Montería.

\begin{tabular}{lccc}
\hline ZoNA & $\begin{array}{c}\text { No de } \\
\text { animales } \\
\text { seropositivos }\end{array}$ & $\begin{array}{c}\text { Total animales } \\
\text { probados }\end{array}$ & $\begin{array}{c}\text { \% de animales } \\
\text { seropositivos } \\
\text { para cada zona }\end{array}$ \\
\hline Norte & 2 & 40 & 5 \\
Oeste & 3 & 40 & 7.5 \\
Este & 9 & 40 & 22.5 \\
Sur & 8 & 43 & 20 \\
Total & 22 & 163 & \\
\hline
\end{tabular}

zonas restantes, el número de animales seropositivos del total muestreados fue: Norte $1.2 \%$, Oeste $1.8 \%$ y Sur $4.9 \%$. No obstante los resultados positivos obtenidos, el análisis estadístico para la variable zona mostró una baja significancia estadística $\left(X^{2}=7.44\right.$, valor de $p=0.059$ ).

En la tabla 2 se puede observar que la mayor seropositividad se encontró en los animales entre 5 y 6 años (4.9\% del total de animales probados), seguido de los menores de 4 y mayores de 7 años ( $4.3 \%$ del total cada uno). El factor edad no tuvo relación significativa con la variable infección a VRSB $\left(X^{2}=0.444, p>0.05\right)$.

Tabla 2. Resultado de serología al VRSB de acuerdo con los grupos etarios.

\begin{tabular}{lccc}
\hline GRUPO ETARIo & Positivos & $\begin{array}{c}\text { Total } \\
\text { animales } \\
\text { probados }\end{array}$ & $\begin{array}{c}\text { \% de animales } \\
\text { seropositivos / } \\
\text { grupo etáreo }\end{array}$ \\
\hline Entre 3 y 4 años & 7 & 53 & 13.2 \\
Entre 5 y 6 años & 8 & 50 & 16 \\
Más de 7 años & 7 & 60 & 11.7 \\
Total & 22 & 163 & \\
\hline
\end{tabular}

En la tabla 3 se observa que en la explotación de carne, 8 bovinos $(4.9 \%$ del total muestreados), mostraron anticuerpos al VRSB en el análisis serológico y 14 bovinos ( $8.6 \%$ del total), fueron reactores en las explotaciones de doble propósito, encontrándose en mayor proporción. Se encontró una débil relación significativa entre las variables analizadas $\left(X^{2}=0.056, p>0.05\right)$.

Tabla 3. Relación seropositividad a VRSB versus tipo de explotación.

\begin{tabular}{lccc}
\hline $\begin{array}{c}\text { Tipo de } \\
\text { explotación }\end{array}$ & Positivos & $\begin{array}{c}\text { Total } \\
\text { animales } \\
\text { probados }\end{array}$ & $\begin{array}{c}\text { \% de animales } \\
\text { seropositivos / } \\
\text { tipo de explotación }\end{array}$ \\
\hline Carne & 8 & 63 & 12.7 \\
Doble Propósito & 14 & 100 & 14 \\
Total & 22 & 163 & \\
\hline
\end{tabular}

Los valores hallados para cada uno de los desórdenes reproductivos (Tabla 4), no mostraron relación con la seropositividad $\left(X^{2}=0.073, p>0.05\right)$, lo que sugiere que la presencia de VRSB es independiente de la condición reproductiva o 
Tabla 4. Relación seropositividad a VRSB con alteraciones reproductivas.

\begin{tabular}{lccc}
\hline $\begin{array}{c}\text { Trastorno } \\
\text { Reproductivo }\end{array}$ & $\begin{array}{c}\text { No de } \\
\text { animales } \\
\text { seropositivos }\end{array}$ & $\begin{array}{c}\text { Total } \\
\text { animales } \\
\text { probados }\end{array}$ & $\begin{array}{c}\text { \% de animales } \\
\text { seropositivos / } \\
\text { tipo de trastorno } \\
\text { reproductivo }\end{array}$ \\
\hline Aborto & 6 & 40 & 15 \\
Repetidoras & 10 & 92 & 10.9 \\
Reabsorciones & 1 & 5 & 20 \\
Total & 17 & 137 & \\
\hline
\end{tabular}

probablemente que el tamaño de la muestra fue insuficiente para demostrar la asociación.

A pesar de la diferencia entre el número de hembras y el número de machos en las muestras recolectadas (Tabla 5); al comparar estadísticamente la relación

Tabla 5. Distribución de la reactividad a ELISA VRSB por sexo.

\begin{tabular}{lccc}
\hline Resultados & Positivos & $\begin{array}{c}\text { Total } \\
\text { animales } \\
\text { probados }\end{array}$ & $\begin{array}{c}\text { \% de animales } \\
\text { seropositivos / } \\
\text { género }\end{array}$ \\
\hline Vacas & 17 & 137 & 12.4 \\
Toros & 5 & 26 & 19.2 \\
Total & 22 & 163 & \\
\hline
\end{tabular}

de su seropositividad con el sexo, no se encontraron diferencias significativas $\left(X^{2}=0.871, p>0.05\right)$; lo que indicaría que no existe susceptibilidad por sexo a la infección con el VRSB.

\section{DISCUSIÓN}

Los resultados obtenidos en el presente estudio, constituyen la evidencia serológica de la actividad del VRSB en el municipio de Montería, Colombia, al haberse encontrado con anticuerpos por ELISA una seropositividad del $13 \%$ de los animales muestreados en ganaderías de carne y doble propósito.

El hecho de haber encontrado en mayor o menor grado sueros positivos procedentes de todas las zonas estudiadas, sugiere que: 1) el virus ha estado circulando en todos los sitios muestreados ó 2) que los animales (o al menos algunos de ellos), proceden de regiones donde el virus ha estado presente.
La infección por VRSB, aparentemente puede observarse en cualquier grupo etario, como se observó en este trabajo, aunque no se hizo el análisis en animales menores de 3 años, pues como reporta la literatura la enfermedad clínica es más frecuente en terneros menores de seis meses (10). Esta seroreactividad en animales adultos sugiere posibles reinfecciones durante el transcurso de su vida.

La mayor proporción de seropositivos en ganado doble propósito coincide con lo reportado por Rebhun (19) quien afirma, que el confinamiento en ganado lechero, puede favorecer las condiciones para una transmisión rápida del VRSB, debido a un mayor estrés ocasionado por el tipo de manejo.

Igualmente, no se encontraron asociaciones estadísticamente significativas entre trastornos reproductivos de las hembras con la seropositividad, aunque si un porcentaje importante de animales seropositivos con alteraciones como repeticiones de servicio, reabsorciones embrionarias y abortos. Será necesario realizar un muestreo mayor para establecer el posible impacto de la infección con VRSB sobre alteraciones como las destacadas en éste estudio. Lo anterior es también válido para la comparación de infección por sexo, que ha sido destacado como un factor de riesgo en machos utilizados para servicio por monta directa o inseminación artificial (20).

En conclusión, al no haberse encontrado historia de vacunación en ninguna de las fincas estudiadas, este hallazgo constituye la demostración indirecta de la circulación del VRSB en la zona de estudio, siendo recomendable el desarrollo de estudios adicionales, para determinar la verdadera importancia de este agente sobre los problemas respiratorios y reproductivos en el ganado bovino de la región, y su participación dentro del complejo bovino conocido como "Fiebre de embarque". De acuerdo con estos resultados sería posible realmente, establecer la necesidad o no de implementar medidas adecuadas para la prevención, control y eventualmente, erradicación de la infección. También sería 
recomendable la realización de estudios sobre la dinámica de anticuerpos en fincas positivas a VRSB, para así determinar la evolución del virus en las áreas afectadas. Finalmente, se propone realizar estudios epidemiológicos con otras técnicas tales como el aislamiento viral, encaminados a demostrar el verdadero impacto clínico que la infección con este agente, puede estar ocasionando sobre la reproducción, y así justificar la conveniencia de aplicar o no inmunógenos específicos, realizando investigaciones relacionadas con de la eficiencia de dichos biológicos en las condiciones del trópico Colombiano.

\section{Agradecimientos}

A la Oficina Administradora de Investigación y Extensión de la Universidad de Córdoba, al laboratorio Novartis de Colombia (Salud Animal).

\section{REFERENCIAS}

1. Hilleman MR. Respiratory Syntitial Virus. Am Rev Respir Dis 1963; 88(SUPPL):181-197.

2. Smith $M H$, Frey $M L$, Dierks RE. Isolation, characterization, and pathogenicity studies of a bovine respiratory syncytial virus. Arch Virol 1975; 47(3):237-47.

3. Van Der Poel WH. Dynamics of bovine respiratory syncitial virus infections, a longitudinal epidemiological study in dairy herds. Arch Virol 1974; 133: 309-321.

4. Rosenquist BD. Isolation of Respiratory Syncytial Virus from cattle with acute respiratory disease. J Infect Dis 1974; 130:177-182.

5. Valarcher JF, Taylor G. Bovine respiratory syncytial virus infection. Vet Res 2007; 38:153-180.

6. Larsen LE. Bovine respiratory syncytial virus (BRSV): a review. Acta Vet Scand 2000; 41: 1-24.

7. Fach SJ, Meyerholz DK, Gallup JM, Ackermann MR, Lehmkuhl HD, Sacco RE. Neonatal Ovine Pulmonary Dendritic Cells Support Bovine Respiratory Syncytial Virus Replication with Enhanced Interleukin (IL)-4 and IL-10. Gene Transcripts. Viral Immunol 2007; 20(1):119-130.
8. Hagglund S, Svensson C, Emanuelson $\mathrm{U}$, Valarcher JF, Alenius S. Dynamics of virus infections involved in the bovine respiratory disease complex in Swedish dairy herds. Vet J 2006; 172: 320-328.

9. Baker JC, Frey ML. Bovine respiratory syncytial virus. Vet Clin North Am Food Anim Pract 1985; 1(2):259-275.

10. Yaegashi G, Seimiya YM, Seki $Y$, Tsunemitsu H. Genetic and antigenic analyses of bovine respiratory syncytial virus detected in Japan. J Vet Med Sci 2005; 67(2):145-150.

11. Beaudeau $F$, Ohlson A, Emanuelson $U$. Associations between Bovine Coronavirus and Bovine Respiratory Syncytial Virus infections and animal performance in Swedish dairy herds. J Dairy Sci 2010; 93(4):1523-1533.

12. Alm K, Koskinen $E$, Vahtiala $S$, Andersson M. Acute BRSV infection in young AI bulls: effect on sperm quality. Reprod Domest Anim 2009; 44(3):456-9.

13. Fulton $R$, Purdy A, Confer A, Saliki J, Loan R, Briggs R, Burge L. Bovine diarrhea viral infections in feeder calves with respiratory disease: interactions with Pasteurella spp, Parainfluenza - 3 virus and bovine respiratory syncytial virus. Can J Vet Res 2000; 64(3):151-159. 
14. Schmidt U, Beyer J, Polster U, Gershwin L, Buchholz U. Mucosal Immunization with live recombinant Bovine Respiratory Syncytial Virus (BRSV) and recombinant BRSV lacking the envelope glycoprotein $G$ protects against challenge with wild-type BRSV. J Virol 2002 76(23): 12355-12359.

15. Vera VJ, Villamil LC, Ramirez GC. Reactividad serológica al virus respiratorio sincitial bovino en un banco de sueros de explotaciones comerciales del altiplano frio. 1a ed. ISSN 0120-2952. Bogotá: Universidad Nacional de Colombia; 2006.

16. IGAC Instituto Geográfico Agustín Codazzi. Comunicación Institucional. Montería: IGAC; 2005.
17. ICA FEDEGAN. Informe censo bovino II ciclo de vacunación AftosaBrucelosis. Comunicación institucional. Bogotá: ICA_FEDEGAN; 2007.

18. Siegel S. Estadística no paramétrica aplicada a las ciencias de la conducta. 4a ed. México: Ed Trillas; 2005.

19. Rebhun WC. Enfermedades del Ganado vacuno lechero. Zaragoza - España: Editorial Acribia SA; 1999.

20. Trevor RA. The epidemiology of BRSV infection. Vet Méd 1993; 88(9):881-885. 